\title{
Magnetotectonics in the Piemont Tertiary Basin
}

\author{
Thio Hong Kie * \\ Paleomagnetic Laboratory 'Fort Hoofddijk', Budapestlaan 17, Utrecht (The Netherlands)
}

(Received June 22, 1987; revision accepted November 4, 1987)

Thio, H.K., 1988. Magnetotectonics in the Piemont Tertiary Basin. Phys. Earth Planet. Inter., 52: 308-319.

\begin{abstract}
Characteristic remanent magnetization (ChRM) directions from late Oligocene sediments of the Piemont Tertiary Basin show a $45^{\circ}$ anticlockwise deviation from the present-day field direction. Up to $30^{\circ}$ of this deviation can be ascribed to large-scale (plate) movements, as deduced from earlier studies. The inclinations show a considerable scatter and are too low for the presumed latitude of the area during the time of deposition.

The samples show a strong anisotropy of magnetic susceptibility (AMS) and in one section there is evidence that the magnetic foliation is produced by the inhomogeneous distribution of titanomagnetite in the specimens. The general pattern of the AMS strongly suggests that the rocks have been deformed with a NW-SE stretching axis. This suggestion is supported by scanning electron microscope observations, which reveal a fabric in accordance with the above-mentioned strain orientations and indicate that the shortening axis makes a small angle with the bedding. It is tentatively assumed that this deformation has resulted in the extra anticlockwise deviation of $15^{\circ}$ of the ChRM directions. Since there were no signs of deformation visible in the field, the AMS proved to be the main indicator for deformation.
\end{abstract}

\section{Introduction}

Anisotropy of magnetic susceptibility (AMS) techniques have often been applied in conjunction with field analysis and microscopic observations of (micro-) fabrics, and a good correlation between the various methods has usually been found (e.g., Hrouda, 1982; Hirt, 1986). However, a potentially more useful application of AMS may be in tectonic studies of non-metamorphosed rocks in which no fabric is discernible in the field, as in a recent study by Kissel et al. (1986). In such a case, AMS may be the only measurable indicator of strain in the region.

In this paper the results of a combined AMS and palaeomagnetic study on fine-grained soft sediments, namely, clays, marls and sandstones, from the Piemont Tertiary Basin are presented,

* Present address: Division of Geological and Planetary Sciences, California Institute of Technology, Pasadena, CA 91125, U.S.A. and the relation with the regional tectonics is discussed.

\section{Geological setting and sampling}

The Piemont Tertiary Basin is situated along the NW fringes of the Apennines, and forms the semi-autochthonous cover of the upper Liguride units (Fig. 1). To the north the basin is bordered by the Varzi-Villalvernia lineament, along which the Antola nappe, the basement of the Piemont Tertiary Basin, was emplaced during the middle Miocene (Den Haan, 1979). The sections which have been sampled for this study lie several kilometres south of the Varzi-Villalvernia lineament, around the town of Garbagna. Here, the rocks are of late Oligocene/early Miocene age (Vervloet, 1966) and structurally form part of the gently dipping eastern limb of the San Sebastiano Curone syncline (Labesse, 1966; Wessels, 1980).

Earlier palaeomagnetic studies in the area on 


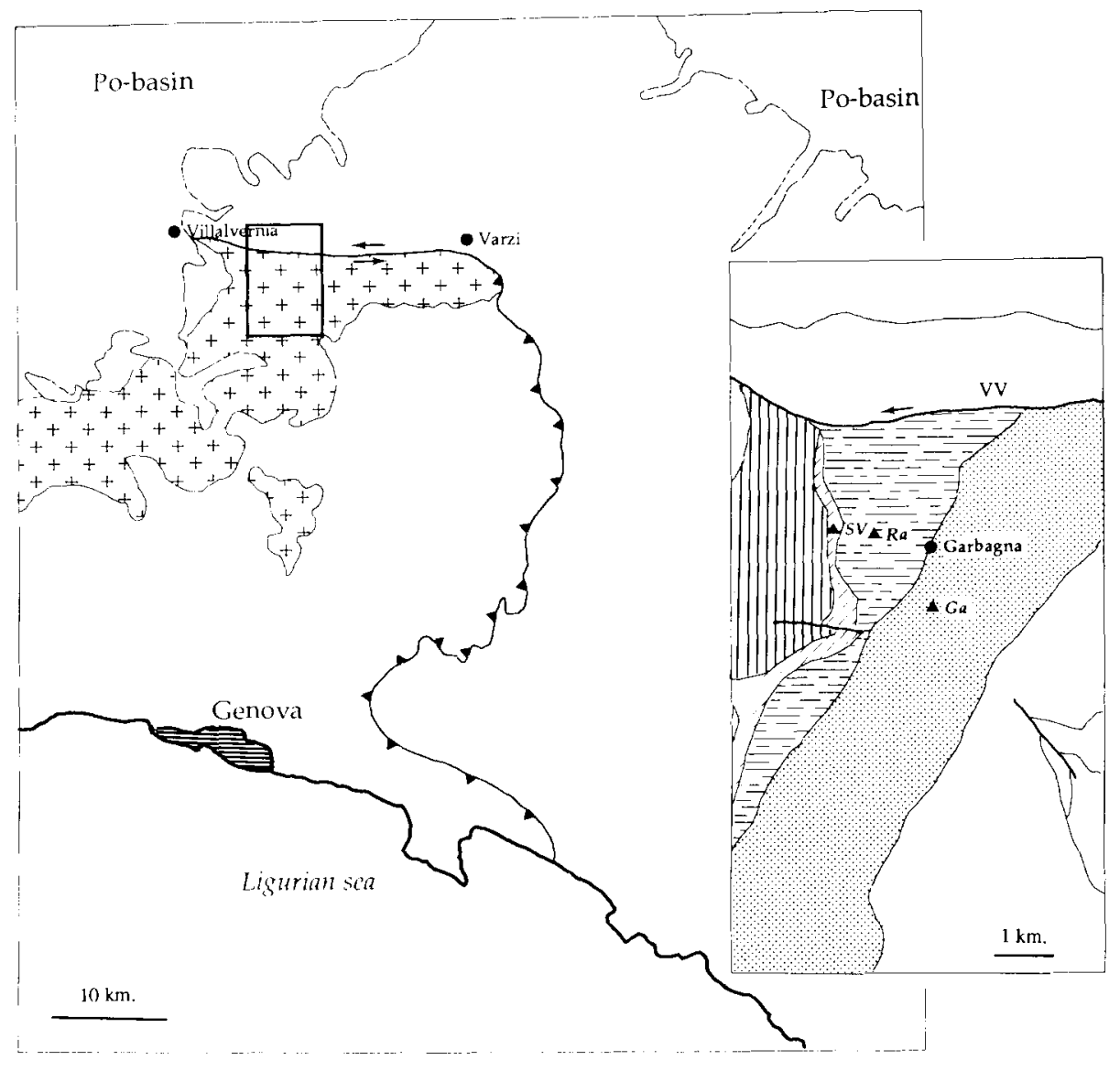

Fig. 1. Map of the margin of the Northern Apennines and the Po Basin (after Den Haan, 1979). The Piemont Tertiary Basin is marked with crosses, while the triangles represent the (thrust) boundary of the Antola unit. The area in the rectangle is the sampling area and is enlarged in the inset (after Vervloet, 1966; Boni, 1969). On this geological sketch-map, the thick lines designate fault structures, VV being the Varzi-Villalvernia lineament, while the thin lines represent stratigraphical boundaries. The sections are marked: Ga-Garbagna section; Ra--Ramero section; SV-San Vito section.

early Oligocene and older rocks by VandenBerg (1979) revealed a $25^{\circ}$ anticlockwise deviation from the present-day field direction. Those sections belong to the same tectonic unit as sections presented here.

Three sections have been sampled, each consisting of several sites on different stratigraphic levels (Fig. 2). In all sections the bedding tilt amounted to $\leqslant 15^{\circ}$, with a NW dip. Only drill cores were taken, using a diamond-tipped brass drill with a diameter of $2.5 \mathrm{~cm}$. Some clay levels could not be sampled due to the dissolution of the clay in the cooling water.
In the oldest section, Garbagna, marls and sandstones were sampled, with some cores taken through the bedding plane and thus containing both a sandy as well as a marly component. The sandstones in particular had to be handled very carefully. The Ramero section consists of very homogeneous clays and the bedding is only rarely visible. This may be due to the intensive bioturbation, the traces of which are abundant and clearly visible under the microscope. Both the Ramero and the Garbagna section are of late Oligocene age. The youngest section is the San Vito section and is made up of clays and marls. At the second 


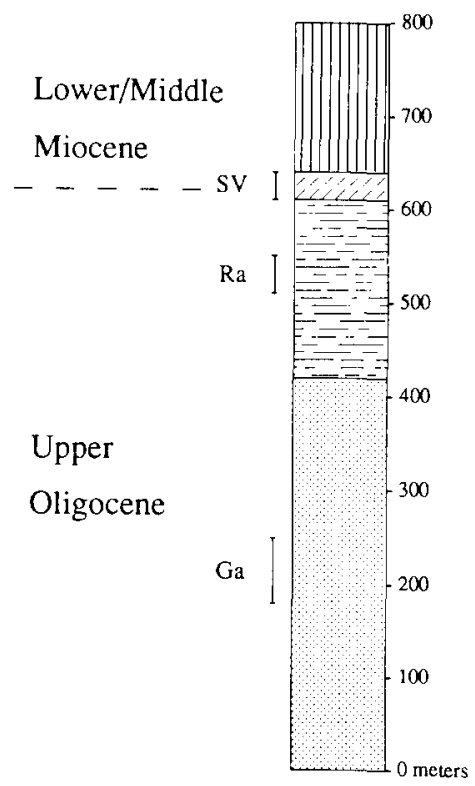

Fig. 2. Stratigraphic column (after Vervloet, 1966; Wessels, 1980), including the sampled levels. Abbreviations for the sections and shading of the formations are the same as in Fig. 1 (inset).

site, coarser green tuffitic fragments are intercalated with the clays. The age of these rocks is late Oligocene/early Miocene. A total of 104 cores was taken at 13 sites (cf. Table I).

\section{Laboratory treatment}

At the 'Fort Hoofddijk' palaeomagnetic laboratory the cores were cut into specimens of $2.2-\mathrm{cm}$ height, which yielded at least two and often three specimens per core. Subsequent measurements of the remanent magnetizations were performed on a two-axis ScT cryogenic magnetometer (Goree and Fuller, 1976) and a JR-3 spinner magnetometer (Jelinek, 1966). All (low-field) susceptibility measurements were performed on a KLY-1 susceptibility bridge (Jelinek, 1973).

From all sites, representative pilot specimens were subjected to progressive demagnetization using either thermal treatment (12 steps up to $650^{\circ} \mathrm{C}$ ) or alternating fields (AF) (16 steps up to $100 \mathrm{mT}$ ). Comparison of AF or thermally treated specimens from the same core showed no systematic difference in direction. However, the directions of the thermally treated specimens showed a greater consistency than those of the AF-treated specimens and a characteristic remanent magnetization (ChRM) could be obtained more accurately with thermal treatment (Fig. 3). Therefore it was decided to subject the bulk of the specimens to thermal demagnetization. Apart from some viscous behaviour at lower steps the demagnetization di-

TABLE I

Statistics of the ChRM and susceptibility, after bedding tilt correction

\begin{tabular}{|c|c|c|c|c|c|c|c|c|}
\hline Section & Site & $N$ & $n$ & $D$ & $I$ & $\alpha_{95}$ & $k$ & $\overline{\bar{\chi}}$ \\
\hline \multirow[t]{3}{*}{ San Vito } & 1 & 13 & - & - & - & - & - & 630 \\
\hline & 2 & 9 & - & - & - & - & - & \\
\hline & 3 & 3 & - & - & - & - & - & \\
\hline \multirow[t]{8}{*}{ Ramero } & 1 & 4 & 4 & 311 & 41 & 12 & 63 & 1350 \\
\hline & 2 & 9 & 9 & 312 & 43 & 8 & 39 & \\
\hline & 3 & 10 & 10 & 318 & 42 & 6 & 69 & \\
\hline & 4 & 10 & 7 & 311 & 34 & 8 & 30 & \\
\hline & 5 & 11 & 11 & 319 & 46 & 6 & 118 & \\
\hline & 6 & 9 & 7 & 325 & 55 & 6 & 94 & \\
\hline & 7 & 7 & 7 & 318 & 33 & 5 & 158 & \\
\hline & Mean & 7 & 7 & 316 & 42 & 6 & 99 & \\
\hline \multirow[t]{4}{*}{ Garbagna } & 1 & 9 & 6 & 145 & -38 & 11 & 41 & 2700 \\
\hline & 2 & 3 & 3 & 131 & -36 & 23 & 31 & \\
\hline & 3 & 7 & 7 & 148 & -18 & 8 & 49 & \\
\hline & Mean & 3 & 3 & 142 & -31 & 20 & 39 & \\
\hline
\end{tabular}

$N$, Total number of samples. $n$, Number of samples used in statistical analysis. $\alpha_{95}$, Circle of $95 \%$ confidence. $k$, Precision parameter. $\bar{\chi}$, Mean susceptibility. 
Demagnetization diagrams

Garbagna \& Ramero sections: thermal demagnetization

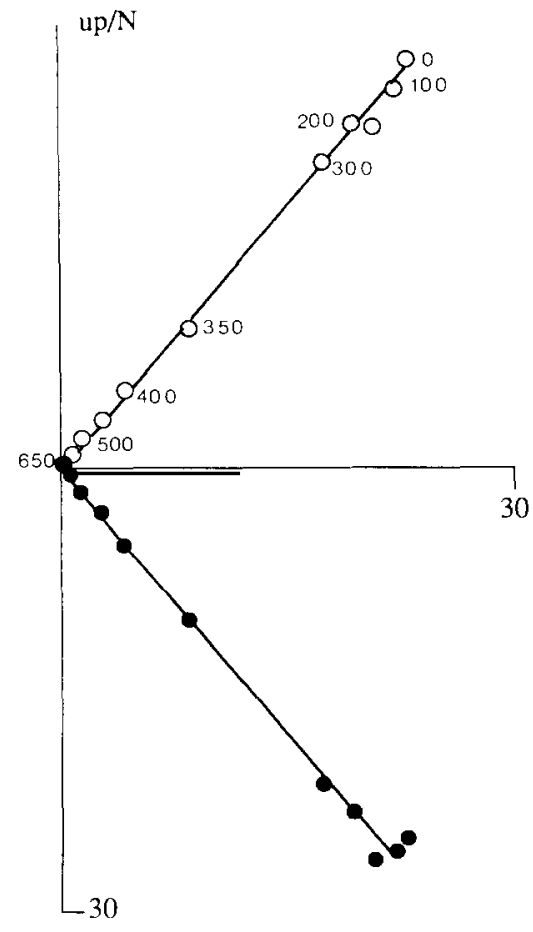

A

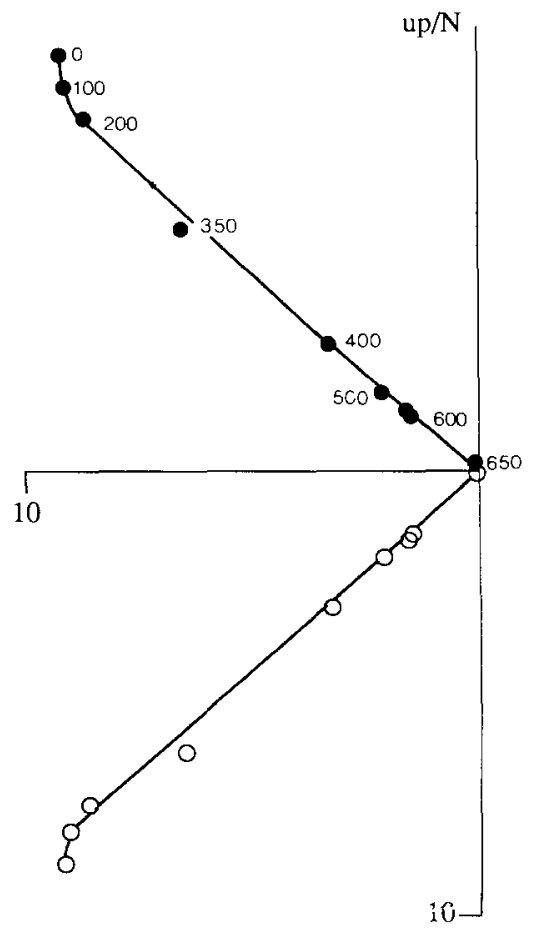

B

Units in $\mathrm{mA} / \mathrm{m}$

Fig. 3. Demagnetization diagrams for thermal demagnetization, without bedding tilt correction: (A) Garbagna section, (B) Ramero section.

agrams show single-component behaviour for the Ramero and Garbagna sections. The initial intensities ranged from 20 to $100 \mathrm{~mA} \mathrm{~m} \mathrm{~m}^{-1}$ for the Ramero section and from 30 to $250 \mathrm{~mA} \mathrm{~m}^{-1}$ for the Garbagna section. Normalized decay curves (Fig. 4) show that most of the magnetization is carried by a low coercive force mineral with an unblocking temperature of $\sim 400^{\circ} \mathrm{C}$, whereas a much smaller amount is carried by a higher coercive force mineral with an unblocking temperature of $\sim 650^{\circ} \mathrm{C}$. This behaviour suggests that titanomagnetite is the main carrier and haematite the subsidiary carrier. The directions carried by the two minerals do not differ significantly. Error estimates of the measurements, based on the overdetermination of the remanence vector, remained
$<2 \%$ until the last one or two steps and even then were rarely $>5 \%$. For the Ramero and Garbagna sections this and the strong alignment of the vector endpoints in the demagnetization diagrams led to an estimation of the within-specimen accuracy of the ChRM directions of $\sim 2^{\circ}$. Specimens from the San Vito section showed a complicated multicomponent behaviour and it was not possible to extract consistent ChRM directions for this section.

The bulk (volume) susceptibilities were quite high in all sections, ranging from 500 to $700 \times 10^{-6}$ SI units in the San Vito section, 1000 to $2000 \times$ $10^{-6} \mathrm{SI}$ units in the Ramero section and 1000 to $6000 \times 10^{-6}$ SI units in the Garbagna section. It may be concluded that titanomagnetite is also the 
Garbagna section: decay curves

AF-demagnetization

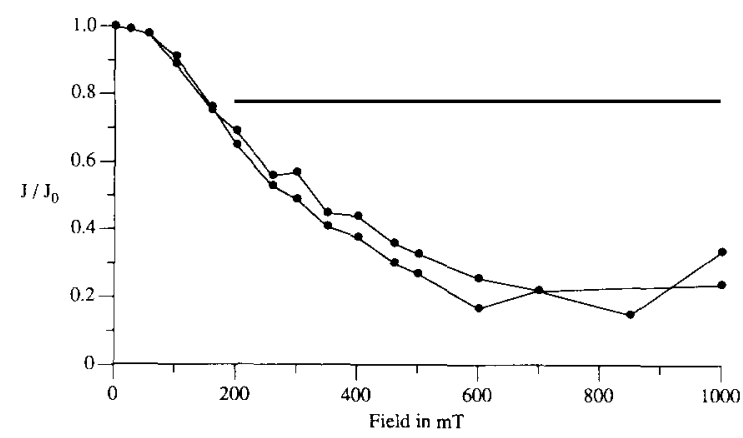

Th-demagnetization

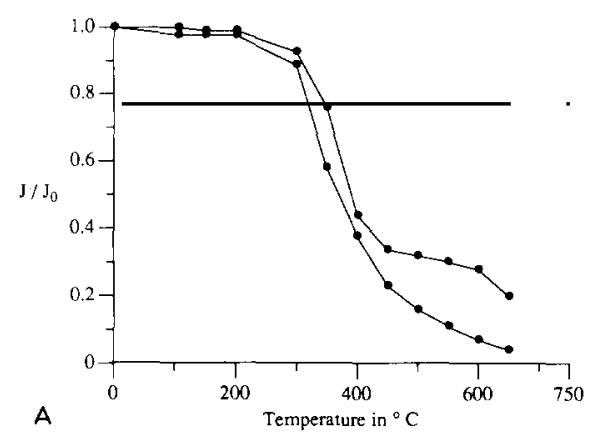

Ramero section: decay curves

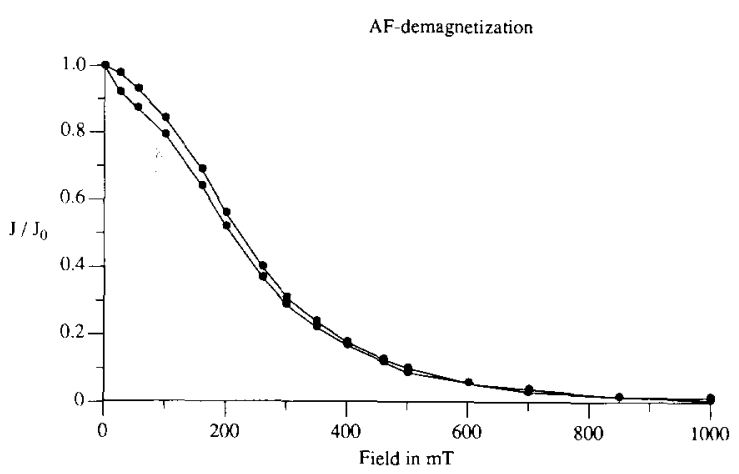

Th-demagnetization

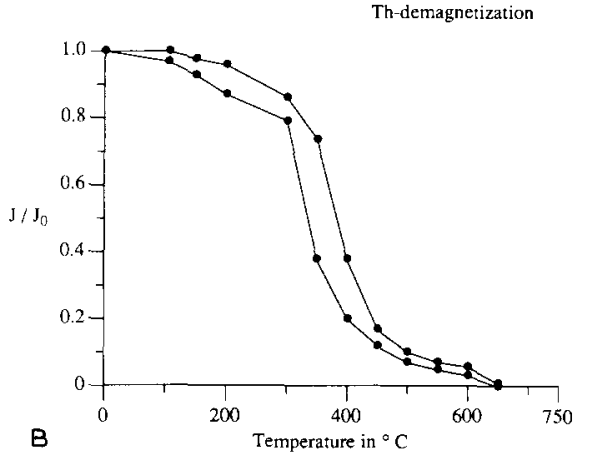

Fig. 4. Normalized decay curves: (A) Garbagna section, (B) Ramero section.

main contributor to the bulk susceptibility. The susceptibility tensor is also based on an overdetermined system of measurements and again the errors found proved to be small, $\ll 1 \%$ in nearly all cases. Only with some of the specimens from the Garbagna section which contain a lithological contrast were deviations higher, up to $2 \%$. This is most probably due to the inhomogeneous distribution of the ferromagnetic particles within the specimen.

An attempt was made to prepare thin-sections to study a possible microfabric in the specimens, but this gave poor results because of the delicacy of the samples, even after they had been heated. It was, however, possible to prepare samples for the scanning electron microscope (SEM). To check against a potential fabric induced by the sawing, the samples were each cut along several planes which were all observable under the SEM. It was also possible to distinguish the ferromagnetic minerals by analysing the secondary electrons.

\section{Results}

The ChRM directions for the Garbagna section (Fig. 5a, Table I) are all of reversed polarity. They show a considerable scatter, both within the sites as well as between the site means. The inclination for all sites and for the third site in particular are much too low for the approximate latitude of the area in the Oligocene. The between-sites $\alpha_{95}$ amounts to $20^{\circ}(N=3)$. Better results were obtained for the Ramero section (Fig. 5b, Table I); this section reveals only normal polarities. Again the mean inclination is too low, in fact only the highest inclinations found are comparable with the expected value of $55^{\circ}$ (VandenBerg, 1979). 
Garbagna section: ChRM directions
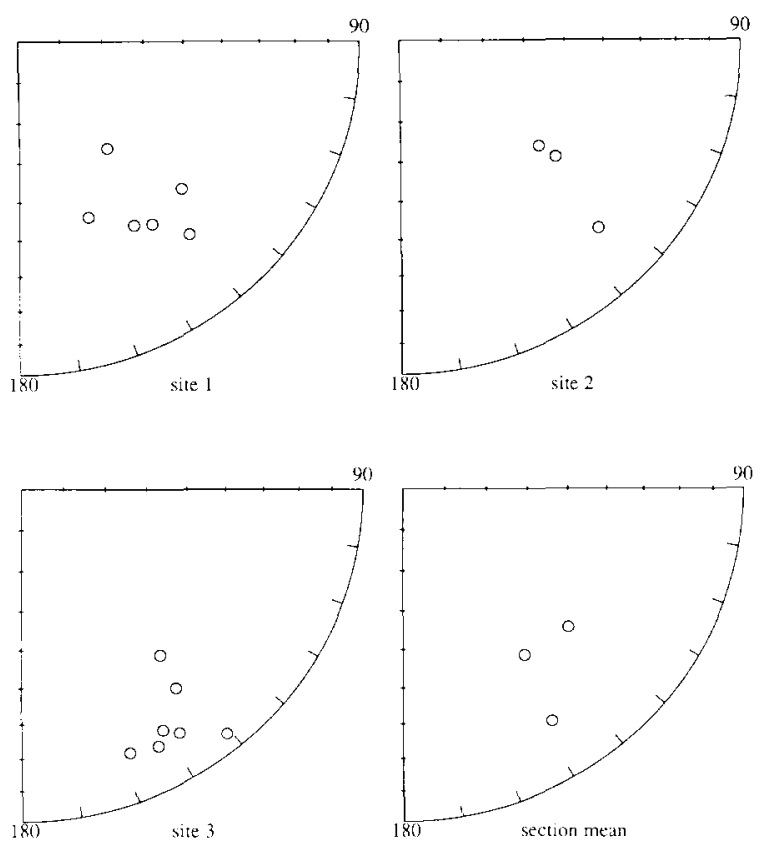

A

The mean declination amounts to $316^{\circ}$, and the between-sites $\alpha_{95}$ is $6^{\circ}(N=7)$.

The shape and magnitude of the AMS are illustrated in Fig. 6, where the magnetic foliation $\left(F=K_{\text {int }} / K_{\min }\right)$ is plotted against the lineation $\left(L=K_{\max } / K_{\text {int }}\right)$. In the Garbagna section the shape of the ellipsoids is clearly oblate with very high foliation ratios, up to 1.45 . The statistics of the directions differ significantly from site to site (Fig. 7a). Whereas the mean direction of the long axes is significant at the third site, it is unclear at the second site and not significant at the first site. However, there is a considerable offset of $K_{\text {min }}$ from the vertical axis $\left(20-30^{\circ}\right)$, which is quite unlike the pattern expected for undisturbed sediments.

Results from the Ramero section (Fig. 7b) show a more uniform picture of concentration of the $K_{\max }$ axes in direction $300^{\circ}$, the same mean direction as the one found at the third site of Garbagna, and again the $K_{\min }$ showing an offset from the vertical, in the same direction as in the Garbagna
Ramero section: ChRM directions
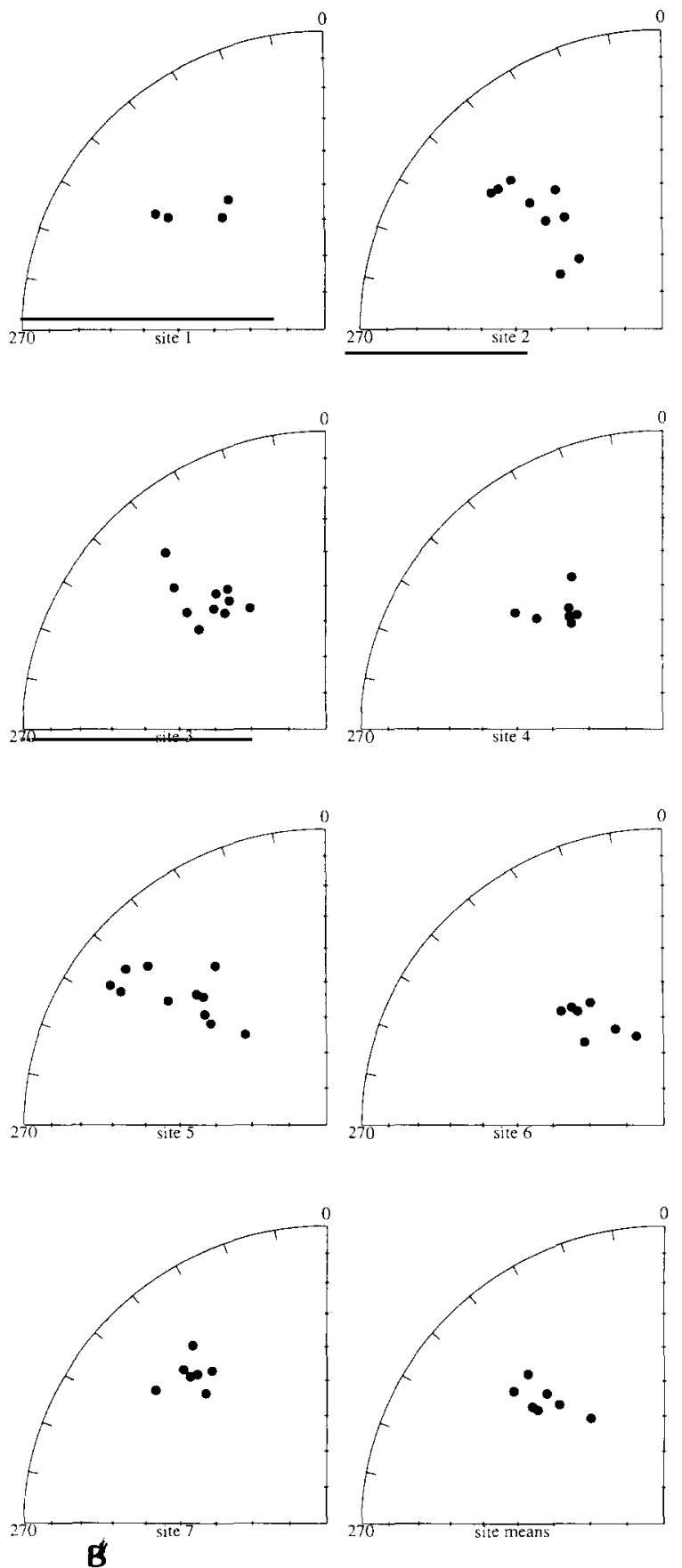

Fig. 5. ChRM directions, after bedding tilt correction; (A) Garbagna section, (B) Ramero section. 


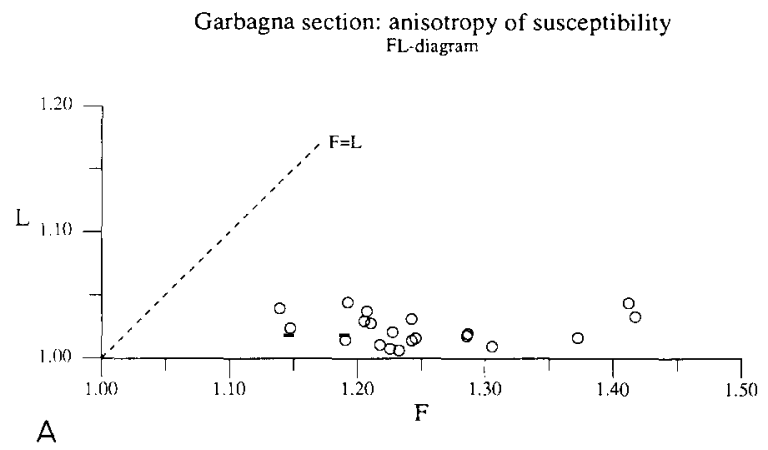

Ramero section: anisotropy of susceptibility
FL-diagram

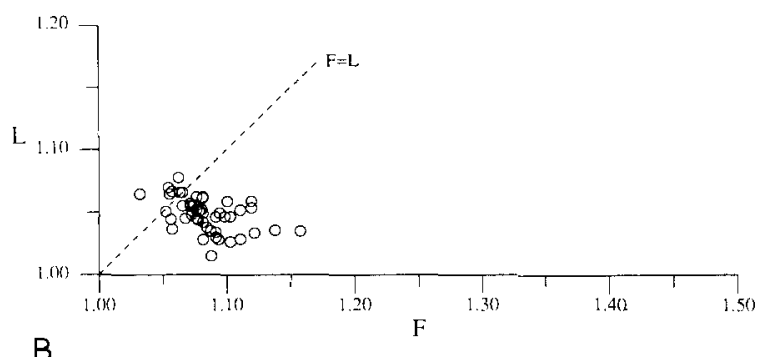

B

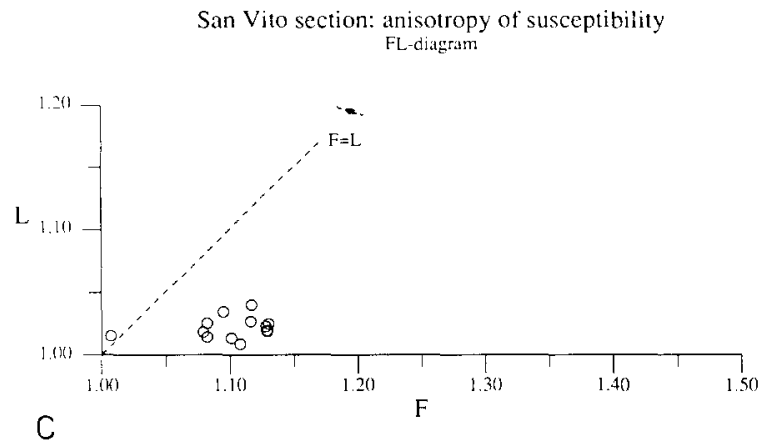

Fig. 6. Foliation and lineation or the magnetic anisotropy: (A) Garbagna section, (B) Ramero section, (C) San Vito section.

section. Note that the $K_{\min }$ axes are distributed predominantly in the very same plane perpendicular to the mean $K_{\max }$, both in the Garbagna and the Ramero sections. The shape of the AMS ellipsoids (Fig. 6b) for the Ramero section is predominantly oblate, although less so than in the Garbagna section. Finally, the AMS of the San Vito section (Fig. 7c) is characterized by a concentration of $K_{\max }$ in direction $330^{\circ}$ and a small offset of $K_{\min }$ from the vertical for both sites.
Scatter is considerably less than in the preceding sections.

SEM photomicrographs show a penetrative fabric made up of clay minerals in the specimens (Fig. 8a-c). Although it is not possible to derive exact orientations from the photomicrographs it can be seen that the fabric makes a large angle with the bedding plane with a NW-SE intersection.

\section{Discussion}

Since all sections are situated in the same limb of the syncline with very similar bedding tilt, no fold test can be carried out. Nevertheless, it is assumed that the ChRM directions are primary. This assumption is based on the following observations:

(1) the ChRM directions are consistent and differ clearly from the present-day field direction;

(2) the reversed and normal directions are antipodal;

(3) the main carrier of the magnetization is (titano) magnetite.

VandenBerg (1979) interpreted the $25^{\circ}$ anticlockwise deviation for the Oligocene and earlier rocks as being due to a major anticlockwise rotation of the Adriatic block during the middle Tertiary, since these results match very well those found for the autochthonous Gargano peninsula (VandenBerg, 1983). The problem now is how we should interpret the present results, which show an extra $15-20^{\circ}$ anticlockwise deviation from the present-day field, in relation to the early Oligocene results. A correct interpretation may be derived from an analysis of the magnetic fabric.

In order to interpret the AMS properly it is necessary to know which minerals are actually responsible for the fabric. In this study, considering the high absolute susceptibility differences between the axes (cf., Fig. 6 and Table I), it is very likely that only minerals with high susceptibility can have caused the AMS measured, in this case (titano)magnetite. The most commonly assumed origin for a fabric determined by titanomagnetite is the alignment of minerals according to their shape. This means that the fabric of the Piemont 
Garbagna section: anisotropy of susceptibility $K_{\max }$ and $K_{\min }$

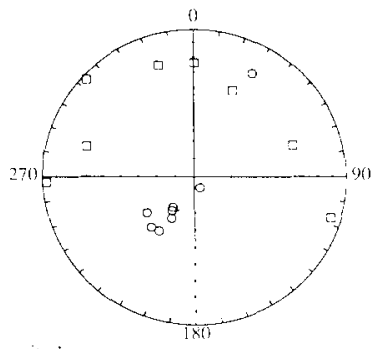

site :

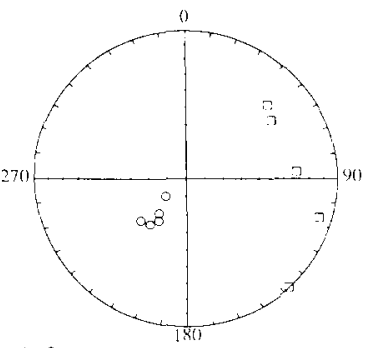

site?

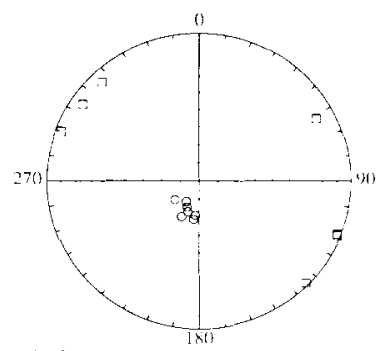

A

San Vito section: anisotropy of susceptibility

$$
K_{\text {tretis }} \text { and } K_{\text {matn }}
$$

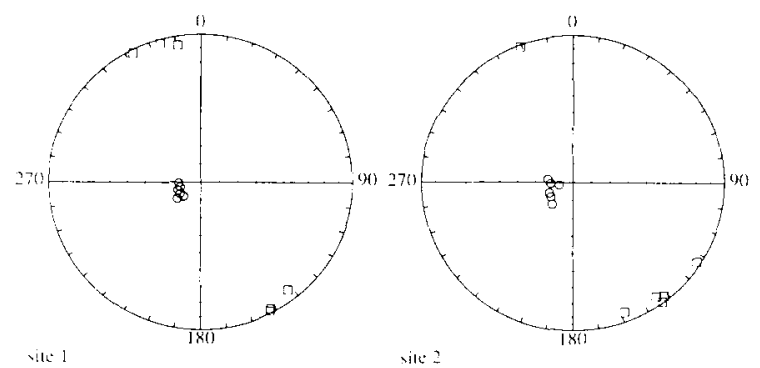

C

\begin{abstract}
vilt.
\end{abstract}

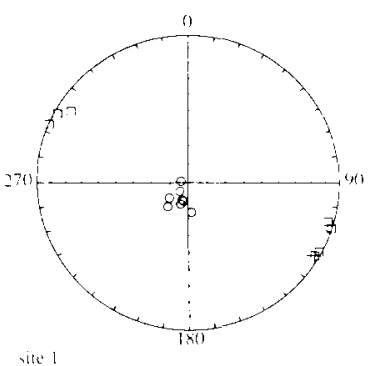

itit

Ramero section: anisotropy of susceptibility

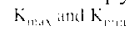

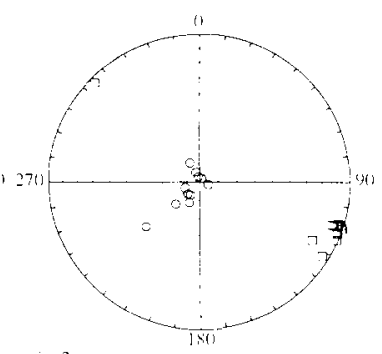

site -
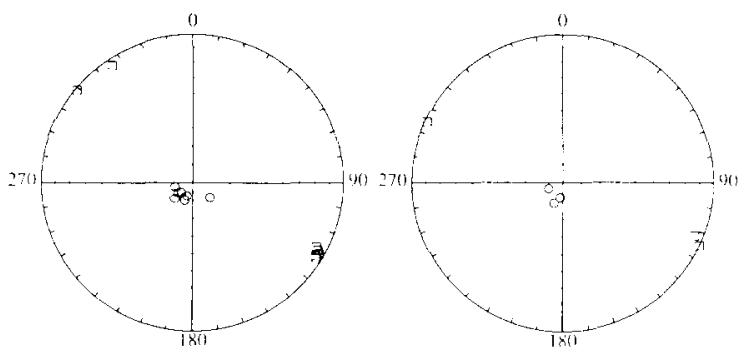

site
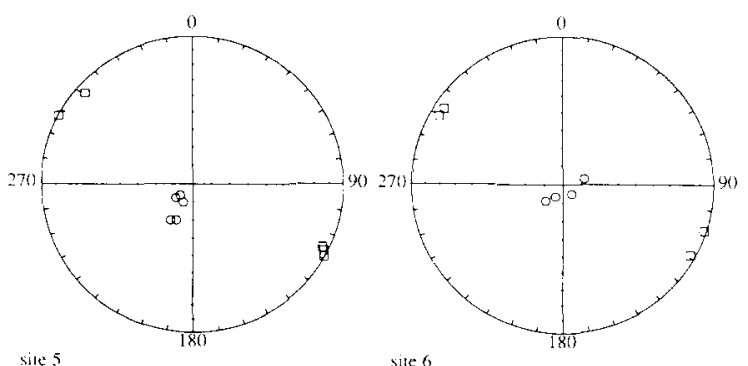

site 6

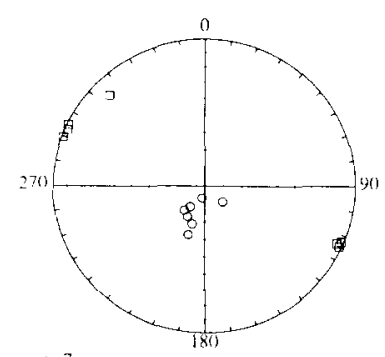

site

Fig. 7. AMS plots, after bedding tilt correction. Lower hemisphere projections: $\square-K_{\max }, \circ-K_{\min }$. (A) Garbagna section, (B) Ramero section, (C) San Vito section. 

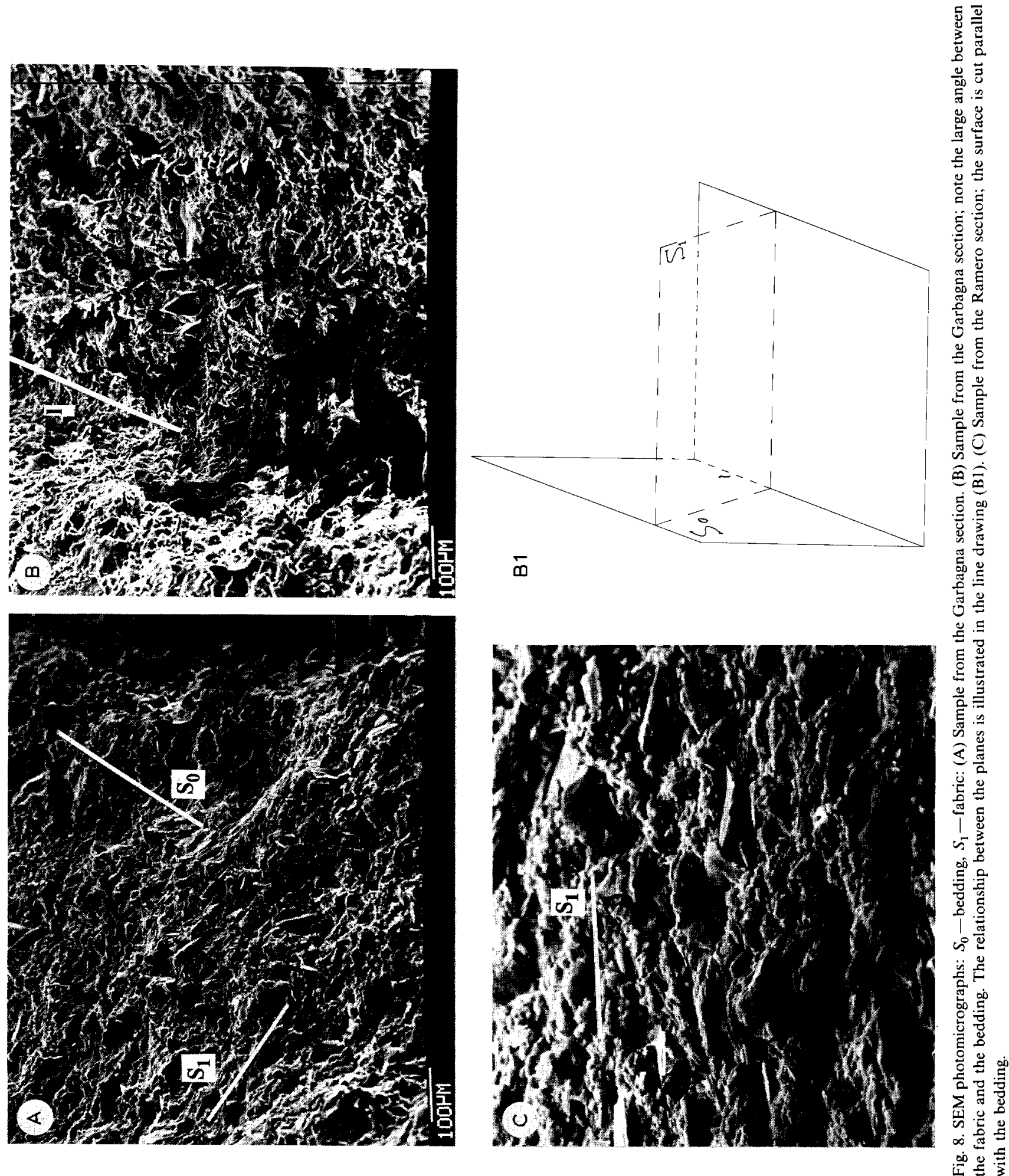

记焉 
samples, with their titanomagnetite content, would be determined by the shape of the grains and the amount of alignment of the grains in a preferential direction (Hrouda, 1982). In this study, however, we also have to take another origin into consideration; the high foliation values for the Garbagna section coincide with the larger standard deviations in the measurements, which have been ascribed to the heterogeneity of the specimen, i.e., the unequal distribution of ferromagnetic minerals between the sandy and marly levels. This should give rise to an oblate fabric parallel to the bedding, and explains at least part of the extreme foliation values.

Various mechanisms can give rise to the formation of a magnetic fabric. The most common are:

(1) alignment of magnetic grains due to bottom flow during sedimentation;

(2) grain rotation induced by compaction or deformation of tectonic origin;

(3) recrystallization in a preferred orientation as a result of deformation or long-term fluid flow in a preferential direction.

It is very unlikely that recrystallization as a result of deformation has occurred, since the rocks are not strongly deformed. Recrystallization in a preferred direction due to fluid flow is a more viable possibility. The $K_{\max }$ axes have roughly the same orientation as the dip of the bedding. Groundwater flow could thus be responsible for recrystallization with an orientation in the direction of the flow, i.e., down-dip (C.J. Spiers, personal communication, 1987). However, SEM and optical photomicrographs show that the ferromagnetic grains have a clastic appearance, which suggests that no significant growth has occurred. Furthermore, there is no consistent second component in the NRM, which might have indicated recrystallization of magnetite.

The alignment of particles due to bottom flow is a well-known mechanism and has often been used as an indicator of flow directions. The fine grain-size of the sediments, especially in the Ramero and San Vito sections, indicates that the bottom flow cannot have been very high. The intensive bioturbation found in these sections which has erased most sedimentary structures suggests that an original magnetic fabric may have been eradicated as well and that the oldest fabric possible is a compactional one. Compaction probably has played a major role in the development of the fabric; the $K_{\text {min }}$ still makes a large angle with the bedding. The problem remains how to explain the strong alignment of the $K_{\max }$ axes and the consistent offset from the vertical of $K_{\text {min }}$. The pattern is similar to the pattern found in earlier studies (Van den Ende, 1977; Lowrie and Hirt, 1987) of deformed sediments. In this case, the $K_{\max }$ orientations would be aligned perpendicular to the axis of maximum shortening, while the $K_{\min }$ axis would eventually be parallel to the axis of maximum shortening, i.e., NE-SW. Additional support for this conclusion comes from the SEM photomicrographs, since the intersection between the bedding and the fabric is roughly parallel to $K_{\max }$ (Fig. 8).

The large angle between the bedding and the fabric, visible on the photomicrographs, indicates that the shortening axis makes a small angle with this bedding. The fact that the $K_{\text {min }}$ makes a much larger angle with the bedding, a position supposedly nearer to the original sedimentary orientation, suggests that the magnetic fabric is not as well developed as the microfabric. The exact orientation of the microfabric may in fact be measurable with high-field AMS equipment, which enables the fabric of the paramagnetic matrix minerals to be determined.

The indications both in the magnetic fabric and in the microfabric for penetrative deformation imply that the ChRM directions cannot be interpreted solely in terms of large-scale movements. In this light it is more appropriate to see whether we can ascribe the deviations found to small-scale deformation. To accomplish this we need, however, some reference from truly undeformed rocks of the same age. This condition is only partly satisfied by the data of VandenBerg (1979) since these come from older rocks while a major anticlockwise rotation of the Adriatic block is thought to have occurred between the early Oligocene and middle Miocene. Nevertheless, they are of some use since they give us a minimum value for the amount of deviation caused by small-scale deformation. If we assume this value, $15-20^{\circ}$, we can see that the sense of the deviation is compatible 
with a strain field with a more or less horizontal NE-SW shortening axis. Such a strain field is incompatible with the orientation of the fold axes in the area, which have a NE-SW trend.

The vicinity of the Varzi-Villalvernia lineament and the related faults within the sampling area may have had an influence on the small-scale deformation in the area. Strike-slip movement would result in a simple shear deformation in the area which is, in fact, also a more efficient mechanism for rotation of the ChRM directions.

The absence of structural markers renders impossible the unstraining of the remanence vectors, proposed, for instance, by Cogné and Perroud (1987), but it may in fact be possible to use the remanence directions, in conjunction with the AMS, to derive quantitative information about the strain in the region.

Apart from the deviating declinations we also have to consider the anomalous inclinations. Anomalously low inclinations have often been reported (e.g., Van den Ende, 1977) and are usually ascribed to compaction, although recently the importance of salinity-dependent flocculation of clay particles has been demonstrated by Van Vreumingen and Zijderveld (1987). At any rate, it is quite apparent that the strain field proposed earlier cannot have resulted in lower inclinations. In the case of the Garbagna section we also have to take into account the deflection of the ambient field during formation of the ChRM within the rocks owing to the high anisotropy. Since this anisotropy is primarily determined by the foliation we expect that only the inclinations are affected and indeed, the lowest inclinations are found for the specimens with the highest foliation values. As already mentioned, these high foliation values can be attributed to a layered distribution of the ferromagnetic particles so that the anisotropy existed even before compaction. Janak (1967) has derived a relationship between the foliation value, the real inclination and the deflection of the inclination due to the refraction of the fieldlines. If we apply this to the data of the Garbagna section (for the other sections the deflection is negligible) we find a deflection of up to $10^{\circ}$, using a presumed real inclination of $55^{\circ}$. Comparison of Figs. $5 \mathrm{~b}$ and 9 shows, however, that even this is not enough to

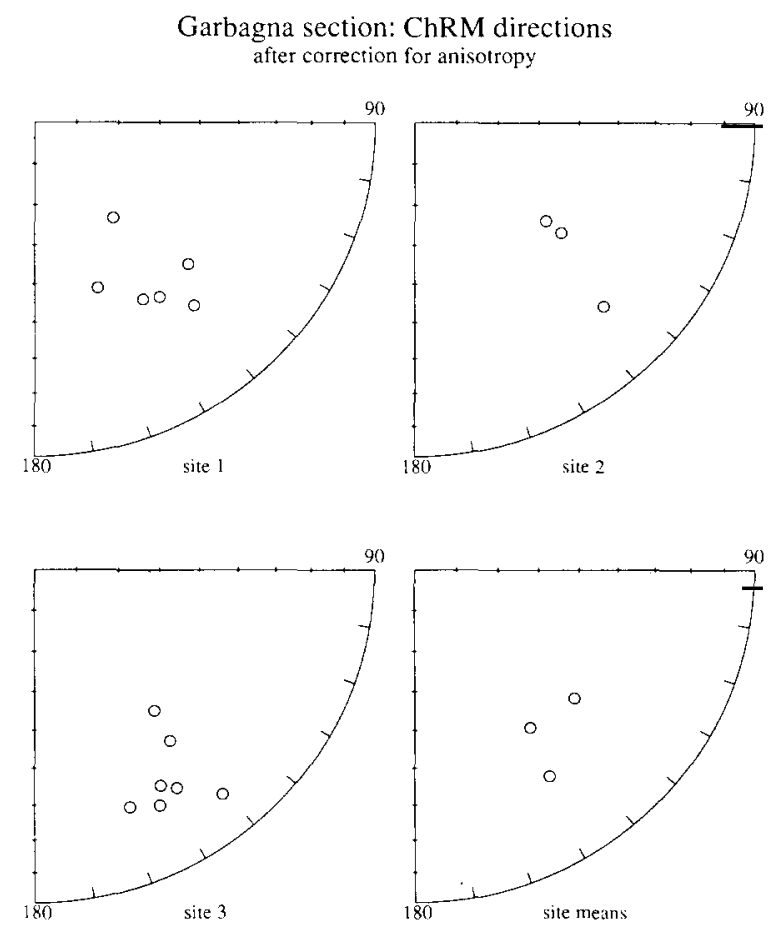

Fig. 9. ChRM directions for the Garbagna section, after correction for magnetic foliation according to Janak (1967).

accommodate the difference in inclination between the Ramero and Garbagna sections, especially since the foliation values were bound to be lower before compaction so that our estimates of the deflection tend to be too high.

\section{Conclusion}

The ChRM directions from the Garbagna area do not agree with the expected directions based on earlier palaeomagnetic studies in the region. The inclinations are too low and although in the Garbagna section the high anisotropy may have had an influence, this phenomenon is still not explained satisfactorily. On the other hand, the extra anticlockwise deviation of at least $15^{\circ}$ can be explained as the result of local deformation. Evidence for this comes from the analysis of the AMS and SEM photomicrographs of the samples, which show that shortening axis has a near-horizontal NE-SW orientation. In this case, the AMS proved to be the main indication for strain. 


\section{Acknowledgements}

I would like to thank Cor Langereis, Cees van den Ende and Prof. Zijderveld for their advice and for reading the manuscript. Herman van Roermund's help was indispensable for the SEM work, Chris Spiers and Mark Dekkers provided some important remarks. The earliest part of this study and the sampling were supervised by Jörgen van den Berg. Roberto Lanza gave a helpful hand in the field.

\section{References}

Boni, A., 1969. Carta geologica d'Italia, Foglio 71, Voghera, Serv. Geol. d'Italia, Roma.

Cogné, J.P. and Perroud, H., 1987. Unstraining paleomagnetic vectors: the current state of debate. EOS, Trans. Am. Geophys. Union, 68 (34): 705.

Den Haan, J.A., 1979. The structure of the window of Bobbio. Geologia Ultraiectina, 23, $116 \mathrm{pp}$.

Goree, W.S. and Fuller, M.D., 1976. Magnetometers using R.F.-driven squids and their application in rock magnetism and paleomagnetism. Rev. Geophys. Space Phys., 14: 591-608.

Hirt, A.M., 1986. Paleomagnetism and magnetic anisotropy techniques applied to tectonically deformed regions. Administration und Druck AG, Zurich, 159 pp.

Hrouda, F., 1982. Magnetic anisotropy of rocks and its application in geology and geophysics. Geophys. Surv., 5: 37-82.
Janak, F., 1967. The effect of anisotropy of magnetic susceptibility on the vector of isothermal remanent polarization. Stud. Geophys. Geod., 11: 419-429.

Jelinek, V., 1966. A high sensitivity spinner magnetometer. Stud. Geophys. Geod., 10: 58-78.

Jelinek, V., 1973. Precision AC bridge set for measuring magnetic susceptibility of rocks and its anisotropy. Stud. Geophys. Geod., 17: 36-48.

Kissel, C., Barrier, E., Laj, C. and Lee, T.Q., 1986. Magnetic fabric in 'undeformed' marine clays from compressional zones. Tectonics, 5 (5): 769-781.

Labesse, B., 1966. Etudes des terraines Eocene et Oligocene du bassin Liguro-Piemontais dans la region de San Sebastiano Curone-Varzi. Bull. Soc. Geol. Fr., 7: 956-966.

Lowrie, W. and Hirt, A.M., 1987. Anisotropy of magnetic susceptibility in the Scaglia Rossa pelagic limestone. Earth Planet. Sci. Lett., 82: 349-356.

VandenBerg, J., 1979. Paleomagnetism and the changing configuration of the western Mediterranean area in the Mesozoic and Cenozoic Eras. Geologia Ultraiectina, 20, 179 pp.

VandenBerg, J., 1983. Reappraisal of paleomagnetic data from Gargano (S. Italy). Tectonophysics, 98: 29-41.

Van den Ende, C., 1977. Paleomagnetism of Permian Redbeds of the Dome de Barrot (S. France). Apollo, Utrecht, $171 \mathrm{pp}$.

Van Vreumingen, M. and Zijderveld, J.D.A., 1987. Flocculation and depositional remanent magnetization. Terra Cognita, 7: 370 .

Vervloet, C.C., 1966. Stratigraphical and micropaleontological Data on the Tertiary of the Southern Piemont (N. Italy). Schotanus and Jens, Utrecht, $88 \mathrm{pp}$.

Wessels, W., 1980. Stratigrafie van het gebied ten NW van de van de Borbera kloof. M.Sc. thesis, Univ. of Utrecht unpublished, $50 \mathrm{pp}$. 